\title{
Why Women Account for Less than Men in STEM Related Industries
}

\author{
Xingshuo Geng ${ }^{1, a, *},{ }^{\dagger}$, and Amanda Huang ${ }^{2, \dagger}$ \\ ${ }^{1}$ College of Arts and Sciences, University of Rochester, Rochester, NY, 14627, United States of America. \\ ${ }^{2}$ School of Qibao Dwight, Shanghai, China. \\ ${ }^{*}$ Corresponding author. Email: ${ }^{a} x g e n g 4 @ u . r o c h e s t e r . e d u$ \\ These authors contributed equally.
}

\begin{abstract}
After identifying the difficult situation in women's problems in STEM industries, we initiated the research by going over the past and ongoing viewpoints and conversations by other scholars. We compared and summarized valuable perspectives brought up by previous researchers and analyzed three possible dimensions that result in the current phenomenon: Education, culture, and biological difference. Then, we ran a detailed analysis of these two facets and discovered some possible reasons such as different treatments in school teachings, the problems of textbooks, gender inequality embedded in cultural values, gender discrimination in the workplace, etc.
\end{abstract}

Keywords: Gender Equity, STEM Industries, Cultural Norm, Biological Difference, Education

\section{INTRODUCTION}

In recent years, the proportion of women is considerably lower than men in STEM (Science, Technology, Engineering, Math) industries throughout many societies worldwide. It even becomes a norm to believe that men are more capable in STEM industries while women are not. Hence, it is crucial to understand the origins and reasons behind it closely correlates with women's well-being and happiness, especially in the workplace. Combined with data and previous analysis, this thesis will analyze the possible reasons why women account for less than men in STEM industries.

As our societies progress, different improvements throughout dimensions outburst, from technology to ideology. Still, among this phenomenal progress, some cultural and sociological issues remain unsettled. Gender inequality stands as a typical instance with impactful influence. According to Julia Wood, a well-known scholar in the field of Gender Studies, gender inequality refers to "Unequal treatment or perceptions of individuals based on their gender. It arises from differences in socially constructed gender roles" [1].Throughout history, this issue can be traced in countless cases: In an early agricultural society, men accounted for most labor work while women were considered inferior and mainly spent time at home taking care of the household. While in modern society, another notable instance that many people are at stake is gender inequality in the workplace, especially in STEM Industries. Typically, in most countries nowadays, women account for less than men in STEM industries, such as engineer and computer science specialists, in terms of the number of occupations, working environment, and salary. It's never a simple coincidence, instead of many factors integrated eventually result in this phenomenon.

Detailing in the current situation, we consulted some recent data and statistics to prove the hypothesis. According to Adeva IT, as of 2019, women held only $25 \%$ of all the jobs in the tech industry, despite women making up almost half of the total workforce. This clearly demonstrates the huge gap in job occupations in the tech industry between males and females. Though these two groups each constitute half of the total labor force in the job market, the distribution in the tech industry seems to be imbalanced to a great extent. Aside from differences in the number of employees and occupations, for those "lucky" winners who earn their parts in STEM industries as female, they also endure great differences in many aspects, sometimes even discrimination. In terms of salary, The ChartHop customer data by Galen Grumen shows women in tech companies make $17.5 \%$ less in wages than men: $\$ 100,895$ on average versus $\$ 122,234$. The percentage difference is slightly bigger than for all women in the US, who make $20 \%$ less than men, on average [2]. This huge and unreasonable gap between 
average salary will also certainly diminish employee's and prospective applicants' passions and interests to some degree. Besides, another gap between males and females in the STEM industry is their role in work. Pew Research Center analysis of U.S. Census Bureau data since 1990 indicates the share of women varies widely across the 74 standard occupations classified as STEM, from under one-in-ten for sales engineers (7\%) and mechanical engineers $(8 \%)$ to $96 \%$ of speech-language pathologists and $95 \%$ of dental hygienists. Women take over most of those working in health-related occupations but just $14 \%$, on average, of those in engineering jobs [3]. The STEM job market seems to retain a stereotypical standard for both sexes: They tend to put the male in their main labor services, from engineers to computer specialists, while female workers seem to be less pivotal and only account for health-related and business-related occupations. To a great extent, this disparity would limit the potential future development of female workers in the STEM industry. They will be restricted in only one to two dimensions and hard to stem out for more opportunities. With the severe and obvious inequality in available occupations, average salary, and division within the industry, women's future career development in the STEM industry will be limited to a great extent. The resources and opportunities are unfairly distributed among male and female workers, thus creates a hostile career environment for women who suffer from this. As a significant and trending topic in the study of inequality among genders, many ongoing studies and conversations regarding this reveal the basic situation and circumstance from a scholarly perspective.

Recently, because of the development of humans and society, the gender gap seems eased. However, gender inequality still usually appears in some respects, such as education. This situation is more obvious in developing countries. Mostly, gender inequality is related to many factors such as poverty, religion, and biology. Although many families nowadays can afford their children's tuition, whatever their genders are, many people face living problems. According to the data from the United Nations, in developing countries, especially in the south of Africa, more than $42 \%$ of people still live under the low-income level, and over 1.6 hundred million children would live in extreme poverty before 2030 . The family's financial situation directly decides if the children can get an education, especially for girls. The proportion between educated males and females is not balanced. For example, women continue to have lower literacy than men, which is $65 \%$ literacy for women and $82 \%$ for men in Egypt, and all India level, the adult literacy rate is $69.3 \%$, and that among males is $78.8 \%$, and females are $59.3 \%$. Through this, we can see that mostly the girls have fewer opportunities of being educated than boys. The literacy rate is related to the number of children. According to the data from Compassion, the degree of education and GDP per capita of a country is higher as the birth rate is lower.
Economics and finance are important for children's education, and the average couple in Australia has 1.77 children whose literacy rate is $99 \%$ (IFS). The Indian women have 2.22 children on average, which rate of literacy is only $40 \%$ for a secondary school in India (Google). The more children a family has, the pressure of tuition of education is higher. As a result, a family with too many children cannot make sure that every child can afford to go to school. However, when a family is facing the problem of choosing a couple of children to go to school, most parents would like to send the boys to the school. According to the ministry of human resource development, 62.1 million children are out of school in India. However, the drop-out rates in Indian school education for girls are $18.3 \%, 32.9 \%$, and $46.7 \%$ in Class(I-V), Class(I-VIII), and Class(I-X), respectively, which are higher than the boys. Also, the total Gross Enrolment Ratio in higher education for women is $19.8 \%$, compared to the boy's $22.3 \%$, which is lower and unfair. As a result, most girls cannot go to school to get educated, and their future would be limited. Even if the females can go to school and get educated, they face inequality in education. This can be presented because in the university, females cannot usually take the courses they want because of their gender. The ratio of women to men is falling as young people move into quantitative careers. In higher education, men are more likely than women to take advanced math and science courses of the bachelor's degrees awarded in 1990, 31.2 percent of those in physical sciences and 13.8 percent of those in engineering were awarded to women. In 1993, only 8 percent of engineers and 9 percent of physicists were women. These choices are important to the career because it is usually related to the advanced-level classes in high school. In that case, even if the women can go to school and get knowledge, they can still have an unlimited future.

Besides the educational causes, many scholars and researchers also concluded that some cultural values and traditions, sometimes even stereotypes, significantly promote severe inequality. They believed some cultural traits, both ancient and contemporary, weaken the recognition of women in the job market, especially in the STEM industry. Detailed conversations and studies were also carried out to address the problem.

\section{LITERATURE REVIEW}

According to Sarah Damaske and Adrianne Frech's study, women's employment is considered to be greatly uneven and stalled [4]. They firstly drew their data from women's weekly work hours in the National Longitudinal Survey of Youth (NLSY79). Then they examined the data and concluded some notable pathways that most women would fall into. To be more specific, most women followed the full-time work pathways, while fewer than $10 \%$ of them followed a pathway of unpaid labor. This 
seems to me, to some extent, that women's pathways toward occupations were already set and determined by some implicit factors. They automatically fell into those norms and pathways when they started to find jobs. Further, Sarah and Adrianne unfolded their studies and delved deeper for some rational explanations [4]. They concluded that the disparity and immobilization are greatly due to work-family conflict. Work-family constraints served to limit women's working hours, as well as their expectations toward occupations. Caring for multiple roles in the modern patrilineal society, women are culturally assigned to support households and spend most of their time at home. This malformed and onesided belief eventually immobilized women's roles and choices of job. Also, the scholars pinpointed some other factors such as social stratification and gender ideologies that came into play in line with work-family constraints to trap women in those settled pathways.

Another study related to cultural influence is the one tracking the effect of motherhood carried out by Lu Yao and her co-workers. They were eager to find out when women became mothers, how their employment trajectories looked like, and the situations and circumstances they were going to face [5]. They employed sequence analysis to trace the entire employment trajectory for a concrete sample of U.S. women, with diversity in age, ethnicity, and race, in their first year following childbirth [5]. They extracted data from the 1996-2008 panels of the Survey of Income and Program Participation and sample selection models [5]. They concluded that women employed before childbirth present a great extent of continuity, which means they mostly stayed in the labor force. However, $24 \%$ of women after childbirth either dropped out or retrograded their occupations. Moreover, mothers' attachment to the labor force and their choices of jobs were significantly constrained by economic hardship and job characteristics. Women after birth found it more difficult to pursue ideal job positions, and they are also unequally treated in the job market with discrimination on capability. Lastly, they went over how the situations were different in different racial groups or types of citizens and concluded that income inequality and political factors also play pivotal roles.

Apart from the social factors, the biological structure will also be a reason for gender inequality. In fact, men and women have different physiological structures, which is normal and should not be a factor of gender inequality. However, some of the differences have become the reason for bias existence, which is generally unfair to women. These can be shown in STEM, a teaching philosophy integrating all four disciplines into a single, interdisciplinary project that guides practical applications and teaching methods [6]. In fact, STEM can help students to have critical and creative thinking. It can also offer a flexible learning model which follows the development of the 21st century well [7]. However, because women language areas in the brain cells to $12 \%$ more than boys, women in the infant can earlier, the period began to speak. The fluency of language learning, comprehension, and literary creativity is better than boys. Women are often thought to be more suitable to study arts than science, so when a girl study science, many people will think that this is inappropriate. At the same time, women tend to pay more attention to details, while men tend to pay more attention to the big picture, which means that on the surface, men are more aware of the 'big picture. And because women are more empathic and perceptive than men, women cry four times more than men, which is why women are more likely to suffer from depression [8]. All of this has contributed to the stereotype that women are less intelligent, weaker, and more in need of protection than men. As a result, people usually consider females as unreasonable which do not fit to learn STEM. In that case, most of the time, females cannot have equal treatment in STEM. STEM is one of the most important sectors to improve the economic competitiveness of European countries. Even in the 21st century, the industry is still dominated by men. A mere 24 percent of STEM professionals in the Netherlands are women, and in actual studies, women feel uncomfortable when they believe they are threatened by gender identity in the industry. At the same time, when people define a person's ability in STEM, many times it depends on gender, not strength, which is extremely unfair to women [9].

\section{GENDER INEQUALITY IN EDUCATION}

Although the grade gap between males and females is not obvious and the number of female graduate students is increasing, which is not much less than males, the number of female teachers is much smaller than the males. The main reason is not about ability but gender. According to the research of gender bias, education evaluations are one of the most important things for a teacher. Gender bias exists in the teaching quality between men and women. According to the previous data, something surprising was that even though the women teachers' education quality is the same as the men's, the evaluation of females is still lower. The result from the boys to female teachers is $12 \%$ lower than they give to males, and the girls are $8 \%$ lower [10]. In fact, not only for the teacher but also for young scholars, the different treatment of females has been a serious problem. Because when it comes to something professional and effective, females cannot receive fair and efficient feedback, which would harm them. Sometimes, the male teachers do the same or even worse as the female teachers have done. However, the students usually only blame the females because they have a gender bias.

In most cases, students are unwilling to treat their teachers alike because they have gender bias, such as 
women cannot teach something with scientific thoughts. However, they have not even realized it. Sometimes, people would lose their trust in the teachers if their gender were female. One thing to note is that when the course is not related to mathematics, boys gave female teachers a standard deviation 17 percent lower than their male peers. For female students, the difference was only 4 percent. However, for mathematics-rich courses, we find greater differences. In these courses, male students rated female instructors about $32 \%$ lower than standard male instructors. The effect is also great for female students: the standard deviation of female teachers in mathematicsrelated courses is about $28 \%$ lower than that of male teachers in these courses [11]. As a result, the bias to the mathematics ability of the female teachers is very serious.

\section{CULTURAL PERSPECTIVE:}

Nowadays, the promotion and propaganda of gender equality are trending and widespread in most societies worldwide. Both governments and scholars are trying hard to eliminate disparity among genders and promote an equal gender environment as part of their missions and social values. With all the above, the inequality and imbalanced relationship between males and females is still visible and prevailing in tons of different facets and dimensions in modern societies. As stressed R. W. Connell in her journal article, "Gender inequalities are embedded in a multidimensional structure of relationships between men and women, which, as the modern sociology of gender shows, operates at every level of human experience, from economic arrangements, culture, and the state to interpersonal relationships and individual emotions" [12].

Significantly, this stigmatized gender relationship and all the unequal traditions or behaviors embedded in modern cultures stand as pivotal factors is resulting in the imbalance of the labor force in the STEM industry. Women are culturally defined and assigned to be less competent, even "inferior" in some cultural backgrounds, leading to the current imbalanced reality. A typical instance of this can be the significantly gendered culture in China. According to Xiongya Gao, a scholar at Southern University at New Orleans, "However, it was Confucianism that turned the marriage system into the bondage of women, treating them as possessions for their husbands" [13]. As he stressed, Confucianism, one of China's most influential ideology schools, maintains a great gender ideology within its values and doctrines. At the origin of China's civilization, it has been a paltriness society. Confucianism was then born in this imbalanced social setting. No doubt, the majority of its embedded theories and ideas are male-centered. As Confucianism gradually became one of China's most representative ideology schools with countless followers and believers, it permeates its gendered understandings and shapes people's mindset and orientation.
Another possible instance within Chinese society can be identified in the ideology of another notable school in China, Taoism. As stressed in Gao's research paper, "The fundamental dualistic outlook, with the differentiation of the Yang (male) and the Yin (female) principles, went back to the Book of Changes, which was later formulated by Confucius" [13]. In China's tradition, from a historical lens, the concept of the gender binary is greatly emphasized in many contexts. As Taoism believes, Yang (male) and Yin (female) are two inseparables elements that maintain the balance in the universe. Hence, males and females are culturally categorized and defined into two separate groups. Since China is a patrilineal society, as mentioned before, the male group would certainly gain a more comparative and absolute advantage in terms of social status, power, etc. This gender principle performs profound and lasting impacts on China's gender relationship to a large extent.

\section{BIOLOGICAL PERSPECTIVE}

In fact, gender has no inequality at the beginning of human's society because the different advantages from biology perspective of males and females could be complementary, which means the different ability from the two genders could cover each other's deficiency. However, since the human society development depended more on physical power such as the military, agriculture, and mathematical thinking, the achievements of the men seemed more efficient than women' s. , and this situation made the most people admire not the specific great men but all men whatever they had contributed. After a long period of this development, this opinion which is incorrect contained in people' mind and became the social bias between males and females.

In the modern society, the contradiction can be the inequality in STEM, because most people think that males are better at mathematical minds, which relates to something important to humans' future, some people seem to unconsciously tend to the males. In that case, the women situation in STEM is not positive. From 2008 to 2015, women only received $34.5 \%$ of Ph.D STEM degrees, and women only got $20.1 \%$ of computer science doctoral degree conferrals in 2016, which was really low[14]. In fact, this result could cause by the bias. However, if it is true that the differences between the structure of the brains of men and women effect their roles in this industry? According to Jill.M. Goldstein from Harvard Medical School, the frontal cortex (the center of many higher cognitive functions) in women is larger than in men, as is the limbic cortex involved in emotional responses. In another hand, the parietal that is to spatial perception in men is larger than in women, and so is the amygdala. The amygdala is an almond-shaped structure that responds to information that provokes emotions - to any information that makes the heartbeat and adrenaline flow [15]. In this case, this might be the 
reason why girls can have a stronger empathy ability. A girl's "understanding" is associated with this structure, and the SG inside the prefrontal lobe affects the skill. However, it has been found that boys are more SG than girls, and girls seem to be more understanding because women develop earlier than boys [16].

As for the differences between the left brain and right brain, one thing is basic that the human brain is not symmetrical. The left hemisphere is responsible for language tasks, while the right hemisphere is responsible for non-verbal tasks. However, according to the experiment from Guilford, women are better at the tasks which relate to language, and men are better and the tasks that the right brain matters, and in the result of mathematical ability tests, the percentage of males was higher than females. However, the result cannot define that woman are not proper to join STEM. Even in 1978, Liwei had put forward the "female brain bilateralization" theory, the main idea is that the male brain is more "lateralization", while the female brain is "bilateralized". Therefore, many disadvantages or drawbacks of males for their left brains could be improved by the roles of females. Besides, the relative inferior position of women right brain is just the general aspect, if the gender bias to women's ability could reduce, the women with STEM ability could contribute to it even more.

\section{CONCLUSION}

In conclusion, the inequality exists in many aspects in our life and history, it is necessary to solve it to protect most people's the rights of most of the people in the world. From the previous research, one thing obvious is that there are some differences between males and females, however, it cannot be the reason of keeping gender inequality because women can also be talented in the field which is seen as the males' traditionally. They are able to deal with important events because their involve areas that men are not good at. From the biology aspect from humanities, women have played an important role in human history and society. If women rights and interests continue to be unprotected, it would be a loss for the. If we can pay attention to our daily lives, we can realize that gender inequality exists in many aspects. It could be a sentence, a textbook, a professional limit, and people's attitude to these events. In the past civilization, women were not treated fairly because people did not have a extend of as in the recent ages, however, as we have noticed the inequality is a serious problem that needed to be solved, we must take actions of it. The requirement is not to destroy the gender, but to understand and accept the differences. In another sentence, the future positive point of the relationship between gender should like respect the gap and do the specialization, instead of the privilege, which should not exist in males or females.

\section{REFERENCES}

[1]. Wood, Julia. Gendered Lives. 6th. Belmont, CA: Wadsworth/Thomson Learning, 2005.

[2]. Gruman, Galen. "Women do Better, Minorities Worse, When it Comes to the Tech Wage Gap." ComputerWorld, Oct 21, 2020.

[3]. Punk, Cary and Parker, Kim. "Women and Men in STEM often at Odds Over Workplace Equity." Paw Research Center Social and Demographic Trends, Jan 9, 2018.

[4]. Damaske, Sarah, and Adrianne Frech. "Women's Work Pathways Across the Life Course." Demography, vol. 53, no. 2, 2016, pp. 365-391.

[5]. Lu, Yao, et al. "Women's Short-Term Employment Trajectories Following Birth: Patterns, Determinants, and Variations by Race/Ethnicity and Nativity." Demography, vol. 54, no. 1, 2017, pp.93118.

[6]. Shelley J. Correll. Gender and the Career Choice Process: The Role of Biased Self-Assessments, University of Wisconsin, Madison, May 2001. $1691-1730$

[7]. Sagala, Umam, Thahir, Saregar and Wardani. The Effectiveness of STEM-Based on Gender Differences: The Impact of Physics Concept Understanding. European Journal of Educational Research, Volume 8, Issue 3, 753 - 761.

[8]. Monica J. Grant and Jere R. Behrman, Population Council, Population and Development Review, March 2010, Vol. 36, No. 1 (MARCH 2010), pp. 71 89

[9]. Ruth van Veelen, Belle Derks and Maaike Dorine Endedijk, Front. Psychol., 19 February 2019

[10]. Gender Bias in Teaching Evaluations Mengel, Sauermann and Zolitz. Journal of the European Economic Association, Volume 17, Issue 2, April 2019, Pages 535-566, 10 February 2018

[11]. Cahill, Larry. "His Brain, Her Brain.” Scientific American, vol. 292, no. 5, 2005, pp. 40-47.

[12]. Connell, R. W. "Change among the Gatekeepers: Men, Masculinities, and Gender Equality in the Global Arena." Signs, vol. 30, no. 3, 2005, pp. 1801-1825.

JSTOR, www.jstor.org/stable/10.1086/427525. Accessed 25 Apr. 2021.

[13]. Gao, Xiongya. "Women Existing for Men: Confucianism and Social Injustice against Women in China." Race, Gender \& Class, vol. 10, no. 3, 2003, pp. 114-125. JSTOR, 
www.jstor.org/stable/41675091. Accessed 2 May 2021.

[14]. Glass, Jennifer L., et al. "What's So Special about STEM? A Comparison of Women's Retention in STEM and Professional Occupations." Social Forces, vol. 92, no. 2, 2013, pp. 723-756.

[15]. Kimura, Doreen. "Sex Differences in the Brain." Scientific American, vol. 267, no. 3, 1992, pp. 118125.
[16]. Halpern, Diane F., et al. "Sex, Math and Scientific Achievement." Scientific American Mind, vol. 18, no. 6, 2007, pp. 44-51. 